\title{
The Perspectives on Emotional Intelligence and its Integration in the Hiring Process as Perceived by HR Practitioners
}

\author{
Rhose Edullan \\ The New England Center for Children. esor4reel2000@yahoo,com
}

\section{Rommel Pilapil Sergio}

Abu Dhabi School of Management.r.sergio@adsm.ac,ae

\begin{abstract}
The study aims to study the perspective of hiring managers and human resource practitioners on emotional intelligence (EI) to evaluate the effectiveness of EI in recruitment assessments and to explore the integration of EI in accelerating recruitment. Qualitative, descriptive, survey, and interview research methods were utilized to examine the assumptions. Purposive sampling technique was used $(n=226)$ to obtain respondents during the COVID-19 pandemic. The research used a thematic analysis to ascertain the responses of the participants. Their EI perspectives were harmonized through the components of EI, and their response to the importance of EI was analyzed through the effectiveness of EI in the work settings and the EI application on hiring. The research has proven the following assumptions: EI is important in work settings, high EI employees are good leaders and better performers compared to high IQ employees, and high EI workers stay with the company for a longer period. Hiring managers and HR practitioners have recommended the integration of EI in the recruitment and practices in United Arab Emirates (UAE) business settings through specific technology-based interventions.
\end{abstract}

Keywords:

Emotional intelligence, hiring process, perspectives, COVID-19, pandemic, technology-based interventions Article Received: 18 October 2020, Revised: 3 November 2020, Accepted: 24 December 2020

\section{INTRODUCTION}

Soft skills have been regarded as human capital dimension; these are imperceptible and nontechnical aptitudes like communication, teamwork, leadership, empathy, problem-solving, and responsibility (Hoffman \& Sergio, 2020; Sergio, Marcano, Ocampo, Oribiana, 2016; Sergio, 2011; Marcano \& Sergio, 2011). Interpersonal skills are the footing of success both in professional and personal facets. People do not live in a fizzy biosphere; whether it is desired or not, interaction and communication with mankind are necessary. As the familiar adage goes, "no man is an island." Therefore, in the sequence of our existence, upright interpersonal skills "oil the wheels" of interactions, creating a pleasing and smooth ambiance for all those who are involved (Need, n.d.).

Moreover, emotions are grand skippers of our being that we unknowingly and religiously submit on them (Gogh, 1889). According to Sanskrit, emotions define us, silhouette our purpose, and outline our perception in life. It is a combination of physical experience, feeling, and thinking. Intelligence, on the other hand, is always associated with cognition and intellect. Emotions are obviously significant to all living creatures that could not be detached from acumen as it is the superior command of intelligence (Gayathri \& Meenakshi, 2013).

Why is emotional intelligence important? The term, which has been abused and misused by popularizers, has a compact scientific underpinning (Cherniss, 2000). Dr. Goleman cited that emotional intelligence is the adeptness of an individual to manage his sentiments and to effectively and appropriately articulate them, which is the major driver of success in the working milieu (Rouse \& Cole, n.d.). It is further outlined "as a form of social intelligence that involves the ability to monitor one's own and other's feelings and emotions, to 
discriminate among them, and to use this information to guide one's thinking and action" (Salovey \& Mayer, 1990).

We evolved in today's fast-moving commercial world, where everyone is so engrossed in striving to make the business stay afloat and sustainable amid a massive threat of competition, shaky economy, and uncontainable and unfortunate occurrences. Edwin Booz believed that "often the best solution to a management problem is the right person." Somehow, according to various studies, behind most successful businesses are emotionally intelligent leaders. Emotional intelligence is an influential tool for taming relationship at work and generating a nourished organizational culture and work atmosphere. An effective leader must have a rock-hard awareness of how emotions and actions influence the surrounding people (Search, 2018).

The efficacy of emotional intelligence in effective leadership is undisputable, but isn't it magnificent if employees also possess superior emotional intelligence? Undoubtedly, human capital is the quintessential intangible asset of an organization. Employees are believed to be the life blood of any association, they can either construct or diminish businesses (Reference, n.d.).

In such case, where employees and emotional intelligence depict superior significance in the business, why can't companies initially embark on board a highly emotionally intelligent job aspirant? It is said: "Hire for attitude, train for skills" (Bill, 2011). Jack Ma elaborated: "You need the right people with you, not the best people." Steve Jobs suggested: "You need to have a collaborative hiring process" to hire the right people.

Hiring process is a process of screening application, picking candidates for the interview, assessing candidates, and deciding who will be hired. Hiring process entails lengthy time to derive to the appointment decision but qualms will keep bugging around if indeed the chosen candidate is the right one, even during the COVID-19 pandemic. Hiring is an expensive procedure, especially if you happened to employ an unsuitable person for the job; imagine the cost it would impact the organization. In this light, a set of recommendations that are technology-based are discussed at the end.

\section{RESEARCH OBJECTIVES}

The paramount objective of this investigation is to answer the research question: Can the implementation of EI in the selection process support HR practitioners in appointing the right employees and elevating job retention? This will be dissected through the following research objectives:

- to explore the perspectives of hiring managers and HR practitioners on the use of $\mathrm{EI}$ in the selection process;

- to evaluate the effectiveness of EI in the recruitment assessments; and

- to provide technology-based interventions in the use of EI in accelerating recruitment.

\section{THEORETICAL BACKGROUND}

The investigation will assimilate Dr. Daniel Goleman's famed Emotional Intelligence Theory (1998). Emotional intelligence is notoriously referred to as EQ (Emotional Quotient) and has been asserted as life's "key to success". Why is emotional intelligence significant? What would the world look like without EI? Visualize a world where you don't apprehend your emotions or you could not distinguish other people's feelings too; it would have been disastrous. Emotional intelligence is the fundamental parcel of experience as a human. It allows people to understand their emotions and that of others too, enabling them to judge and craft decisions - an exclusive human encounter. Emotional intelligence offers life with essence (Craig, n.d.; Sergio, 2011; Marcano \& Sergio, 2011; Sergio et. al., 2015).

Intelligence signifies "to the unique human mental ability to handle and reason about information" (Mayer, et al., 2008). Consequently, in a larger extent, Aron Keith Barbey (2013) stated: 
"Intelligence does depend on basic cognitive abilities, like attention, perception, memory and language. But it also depends on interacting with other people. Humanoids are fundamentally social beings and their understanding not only involves basic cognitive abilities but also involves productively applying those abilities to social situations so that they can navigate the social world and understand others" (Ghose, 2013). According to Mayer et al (2004), "Emotional intelligence fallouts from the interaction of emotion and intelligence" (Mayer, et al., 1999). Therefore, EI denotes a person's ability to comprehend and handle emotions (Craig, n.d.). People who keep their composure with grace even at the utmost awkward situations, and who continually make other people at ease are referred by psychologist as emotionally intelligent. Experts also argue that this nature of intelligence plays a "vital role in success". Many have claimed that EQ is far more relevant than IQ since EQ is interrelated to everything, from making decision to academic realization (Cherry, 2020). Dr. Daniel Goleman even stressed that it isn't technical skills or IQ that distinguish a good leader; it's emotional intelligence. He further that "IQ and technical skills are important, but emotional intelligence is the sine qua non of leadership" (Goleman, 2004). But the question now is: Can emotional intelligence be learned?

Scientifically, it is suggested that emotional intelligence has a genetic component; however, development and psychological study specified that nature affects as well. Perhaps, it could not be known how much of which respectively, but the good news is, practice and research transparently validate that somehow emotional intelligence can be learned. Certainly, as people aged emotional intelligence increases too, like an old-fashioned expression for the portent: maturity. But maturity is not even a guarantee; there are still people that needed training to develop their EI (Goleman, 2004).

Apparently, "emotional intelligence is in the neurotransmitter of the brain's limbic system that governs feelings, impulses, and drives." The study implies that the limbic system absorbs best in extended practice, motivation, and feedback. Whereas, analytical and technical ability is administered from neocortex that clutches logic and concepts. Mistakenly but believed by many, it is the portion of the brain beleaguered by most training platforms intended at improving EI. However, according to the Consortium for Research on Emotional Intelligence in Organization, when the programs yield in effect through neocortical approach, it presents a negative impression on a person's performance in the job. For better enhancement of emotional intelligence, it is necessitating to include in the training the limbic system. People should be aided to modify old conduct to build a new one which demands an individualized style. Moreover, this process leads to an unwavering result through constant practice and persistence. Polishing emotional intelligence will only happen with constant effort and sincere desire (Goleman, 2004).

Motivation is fundamental in emotional intelligence. Emotionally intelligent people are motivated yonder peripheral rewards such as money, acclaim, and fame. But instead, they are passionate to live up to their inner needs and goals. They chase things that fetch experience and internal rewards. They are action-oriented, set goals and strive to achieve them, and always find ways to be better version of themselves. Most of all, they are committed and initiate things when given a task (Cherry, 2020).

Empathy is the most prominent component of EI. It is the proficiency to grasp other people's feelings, beyond being just able to diagnose other people's emotional state. Being empathetic enables people to comprehend the dominance dynamics that oftentimes stimulate social relationships specifically in the work environment. They can intuit who possess power in various relationships, apprehend how these forces impact behaviors and feelings, and precisely construe diverse settings that hinge on that power dynamics (Cherry, 2020). 
Social skills, unlike the primary three elements of EI which are "self-management skills," refer to the ability of the person to manage his relationship with others. Social skills are not merely being friendly; it is friendliness with purpose. It requires influencing people in a desired direction, either an agreement on fresh marketing strategies or eagerness on a new product. People who are socially skilled tend to have vast circle of connections; they have the ability to find collective ground with all kinds of people - best at establishing rapport. It doesn't mean that they continually socialize but they live by the assumption that nothing essential gets through alone (Goleman, 2004).

Dr. Goleman's components of EI corresponds to Bar-On's (1982) Bar-On Emotional Quotient Inventory (EQ-i), which is designed to assess the "emotional and social competencies." This model points out that "emotional-social intelligence is a cross-section of interrelated emotional and social competencies, skills and facilitators that determine how effectively people understand and express themselves, understand others and relate with them, and cope with daily demands" (Bar-On, 1997). Convinced by the arguments of these two extraordinary people, the researchers felt the eagerness and enthusiasm to impart precious knowledge on emotional intelligence in succeeding studies.

\section{LITERATURE REVIEW}

Review of the literature is crucial in every research as it helps in shunning mistakes in previous researches. In this way, the researcher will be guided to improve the research instrumentation and design, which was unfortunately unsuccessful in the past (Cottrell \& McKenzie, 2011). A wellwritten literature review launches a creditability of the report of the student so he can gain from his effort (Leary, 2004). This investigation explores on different literatures endorse and decode the intent of the study. It gathers insightful perceptions on emotional intelligence that lead to conclusion that incorporation of emotional intelligence in administering recruitment is necessitous.

\section{Social View of Emotional Intelligence and Basis for Organizational Support}

When a research in Midwest United States was undertaken with 2,521 part-time MBA students as participants, they were being tested with self-rated and ability measures. Participants were asked to let somebody rate them but that are known to them. They let their supervisor and peer rate them also. The investigation was to examine the social perception of emotional intelligence. The authors contend that people disparage others on their societal skills background. This verdict is then applied in a positive or negative way. Furthermore, researchers resolved that the conviction of EI of the spectators is momentous (Elfenbein, et al., 2015). The research mandates distinct sample to originate from the fundamental hunch which is implausible to be applied in the current research. Though impact of the survey is advantageous and visible to any presented events in a business setting. However, pursuing a specific experimentation will not be valuable for a more solid and concurrent interpretation considering the restricted time allotted for the accomplishment of the research.

The study "Emotional intelligence, work/family conflict and work values among customer service representatives: Basis for organizational support" (Sergio, et al., 2015) purposely selected 437 customer service representatives from Pakistan, Middle East, Russia, Iran, Philippines, and India. Researchers utilized descriptive and comparativecorrelational methods to complete the study that initially aimed to "find the correlates of emotional intelligence such as work/family conflict and work values." The study suggests that "there is a significant relationship between emotional intelligence and work/family conflict, particularly in the areas of self-management, social awareness, and relationship management." It further recommends that organizational development programs should give emphasis to support the 
diversity management in setting directions for call center companies (Sergio, et al., 2015). The scope of this investigation is impressively broad as it covers Asian and European continents. The ongoing investigation will simply focus in UAE commercial settings but its recommendations will not be limited but will be applicable as a general.

Uncountable studies recommend that recognizing and coping with own emotions and contemplating those of others is essential to potent liaisons. It further suggests that a person with exceptional EQ surpasses in the pitch of interaction, collision solutions, individual growth, and team constructing. Features that urge internal auditors must seize to construct and reinforce cohesion amongst clients and people across them to safeguard and intensify the significance of the establishment (Jacka, 2018).

Ostensibly, the above analysis was proven and adapted in contemporary business condition that was remarked in Slovakia. The study plans to delineate the tactical element of "emotional intelligence in the trendy method of Human Resources." The study uncovers that EQ is the contributing factor of the operational functions of leaders and managers (Viskupicova, 2016). Mutual reviews communicated pertinent visions; however, it was determined as purely centered on observations. This reaches exactitude that this research should stick to the implied descriptive methodology for a more truthful, persuasive, and rational concerns.

\section{Emotional Intelligence as an Evaluation Instrument}

Contrary to the previous explorations where EI was sensible in the work environment, the superseding assessment endeavors to expose if matters correlating to conduct, productivity, and performance are influenced by EI or not. Distinct writings were contrasted to demonstrate the theory as EI highlights a terrific position to govern out variations among job contenders. Nonetheless, Fox and Spector favored that EI performs a crucial task in selecting fitting applicants (Fox \& Spector, 2002). Additionally, it indicates that the utilization of an efficient EI in the employment procedure can help in deciding the appropriate candidate that could lead to lengthier service tenure since they are buoyant to acclimatize organizational culture. It was also assumed that obtaining the appropriate fit of individuals on board diminished turnover rates which enhanced productive endeavors of the company (Atak \& Ceylan, 2015).

Evidently, in Turkey a survey on the banking sector was performed by harnessing EI and IQ to help HR professionals in deciding job applicants. The inference was reached when they circulated survey questionnaires to the workforce of several banks to specify their predispositions correspondingly to the aspects of EQ and IQ with respect to the member of staff whom they envision as the ultimate successful in their division. Researchers completed that IQ counts most and it oozes brilliant execution but the connection of EQ and IQ in routine supremacy is clear and compelling. Consequently, both IQ and EQ should be assimilated in the appraisal method to hire "high-performing" personalities in the company (Aydin, et al., 2005).

Likewise, an additional probe is with consistency that EI should be a vehicle for staffing a prospective appointment. The research was operated in the acceptance course in Brock University, Canada for accounting students. Suitably, if accounting education collapses to explicate EI ingenuities, trainees could be less eligible to the recruiters. They have analyzed that students can intentionally adjust their results using EQ-I and MSCEIT test to be an acceptable fit to the job description. The investigation further advised that either of the examinations is cleverest to be used in the employing process because results can be swayed by probable applicants; instead, a revision of the test is required (Nicholls, et al., 2012).

Preceding literatures are astute, and proofs are placed out stressing on the effect of Emotional 
Intelligence in the employment movement nonetheless, the methodology used is self-testing and observational which, in a way, is ludicrous if coated in this research. With lucidity, this investigation should grip a deductive style to offer forthcoming readers a more articulate demonstrated validation.

\section{Emotional Intelligence Envisions Job Performance}

In addition, an investigation decided to reassess and revise the customary confirmations for mixed EI, considering earlier indications of mixed emotional intelligence procedures. Authors extracted inference that mixed EI can actively anticipate job performance, extracting the "cognitive ability and big five personality traits". The examination applied a meta-analysis and hinted that mixed EI foretells job performance evaluations of supervisors associated to other developmental structure (Joseph, et al., 2015). The meta-analytic technique is just dubious if utilized in this investigation possibly because of its experimental context. But the general sanction of EI forecasting job performance is remarkable and, if noted, will be valuable to every companies, particularly if mixed EI is perceived at the beginning phase of lodging prospective personnel.

Evidently, the consistency of the argument of the antecedent study was already undertaken with prior research done in Middle East. The study "Emotional intelligence and demographic profile variables as predictors of job performance among bank managers" (Sergio \& Marcano, 2013) nubs on the job performance determinants like emotional intelligence and demographic profiles variables. The study was conducted among 134 bank managers in UAE, Kingdom of Suadi Arabia, Oman, and Qatar. The research method used was descriptive and correlational to discover the demographic profile and assessing its relationship. "Demographic profile variables were age, status, educational attainment and tenure of work." This study applied "Demographic Profile Sheet, ECI and standard Performance Appraisal for
Managers." This research uncovers that the "relationship between emotional intelligence and job performance is exceedingly significant." It further connoted that there is a significance "between the relationship of job performance and demographic profile variables such as age, civil status, and educational attainment but not with work tenure" (Sergio \& Marcano, 2013). The current study yearned to verify further so that it can also vouch the utilization of emotional intelligence assessment in the hiring process.

In magnifying the research gaps, numerous studies about emotional intelligence were done and various methodologies were implored to delve the core substance and prove its effectiveness. Most of the encountered studies toiled methods such as observation, comparative-correlational, testing, meta-analysis, and correlational. Indisputably, the significance of emotional intelligence is manifested in social view, on relational bonds, as an evaluation instrument and can forecast job performance. Hence, the current study will focus on the "integration of emotional intelligence in the hiring process." This is exceptional as there is no previous study formulated yet. Though the study is constrained in UAE setting only, it will still pave way for new opportunity for future studies because this research will streamline both the quantitative and qualitative methods hardly used in erstwhile investigations. This research is guided and has illuminated the framed assumptions.

\section{RESEARCH METHODOLOGY}

The researchers employed the qualitativedescriptive, survey methods to effectively gather data from the primary sources and make a thorough analysis. In this investigation, the researchers initiated a survey to gather primary data. The survey questionnaire was in a form of Likert scale, and closed and open-ended questions were formulated. The survey questionnaire was disseminated among managers, HR managers, and HR personnel to get their views and opinions about emotional intelligence. The targeted sample, 
through purposive sampling, determined the respondents of the study $(n=226)$. The respondents were HR managers and hiring mangers that directly decide the organization's onboarding or selection process such as general manager, CEO and department managers, and HR head. Participants were selected from various business sectors in the UAE. The questionnaire was digitally sent out for easy access and collection of data prior to actual interview via online platform due to the coronavirus pandemic, which obliged to shun close contact with people. The thematic analysis of data was generated after the data was gathered. In the pursuit of this research, the researchers observed and strictly adhered to the code of ethics imposed by the UAE.

\section{RESULTS AND DISCUSSION}

This research was initially suggested to proceed with qualitative method or personal interviews with the participants to better grasp their views and opinions about emotional intelligence. However, an unprecedented time of coronavirus pandemic impeded the pursuant of the procedure.

\section{The perspective of hiring managers and $H R$ practitioners on the use of EI in selection process} Among the 226 respondents, 60\% $(n=136)$ are hiring managers and $40 \% \quad(n=90)$ are HR professionals. The thematic analysis harnessed a written analysis to ascertain appropriate emotional intelligence components from the articulate responses of the participants. Essentially, the participants' indulgence of emotional intelligence is in consistency with Goleman's (1998) description of EI as their answers harmonize with the component of EI. Being able to get their interpretations helped the researchers determined the possibility of engaging the integration of emotional intelligence in the hiring process. The opportunity becomes clearer because the people who are responsible in the recruitment process fully understood and aware of what EI is.

Theme 1: EI makes a good leader and a good performer
Evidently, according to the respondents, EI performs a significant role in the working environment. For a better understanding of emotional intelligence in work venues, participants' excerpts were categorized to the emerging characteristics of an emotionally intelligent employee in the company as good leader and good performer. The emerging EI theme is "Employee makes a good leader and a good performer" - an asset to the company that brings involvement in achieving the organization's goal. The research finding has given emphasis on the substance and magnitude of emotional intelligence in work settings, and has concurred to the researches done by Joseph et al., 2015; Sergio \& Marcano, 2013, Sergio et al., 2015. Time and again, it has proven that emotional intelligence is a determinant factor of job performance. Higly emotionally intelligent individual makes a good leader and a good performer which is extensively a vital mechanism to marshal attainment of organization's goal. Emotionally intelligent people also exude motivation to influence other people positively. This finding has coincided with Dr. Goleman's arguments “that it isn't technical skills or IQ that distinguished a good leader, it's emotional intelligence." These arguments are also supported by the studies of Joseph et al., 2015 and Sergio \& Marcano, 2013.

\section{Theme 2: EI supports retention}

The results point that the higher the EI, the higher the retention rate wherein there is a high level of employment longevity. It is noted that hiring is a lucrative process and retaining trained employees saves and increases productivity and profitability of the company. This theme supports that individuals are likely to settle in the firm for a period of time because they fully acknowledge themselves and they handle themselves well in workplace relationships. The research finding also confirms with the study of Atak \& Ceylan (2015) that hiring the right employees will slow down turnover rates. The excerpts from the participants were analyzed as EI assessment if integrated or not integrated in the companies' employment 
procedures. The researchers found that most of the companies are not really considering to officially have an emotional intelligence assessment in their hiring procedure.

\section{The effectiveness of $E I$ in the recruitment assessments}

People turnover is foreseeable in any company. But haste and rampant turnover, which has become the ultimate justifications of a declining productivity and loss profit, can be minimized if the company has the right people. Hiring emotionally intelligent individuals can make a difference in the company as perceived by the respondents. Furthermore, the contentions of integrating emotional intelligence in the hiring process has been supplemented by previous investigations such as "Emotions in the workplace - The neglected side of organizational life introduction" by Fox \& Spector, 2002, "The impact of IQ and EQ on pre-eminent achievement in organizations: Implications for the hiring decision of HRM specialists" by Aydin, et al., 2005, "Emotional Intelligence Test: Potential Impacts on Hiring Process for Accounting Students" by Nicholls, et al., 2012, and "Use of emotional intelligence on the selection of human resources" by Atak \& Ceylan, 2015.

\section{Technology-based interventions in the use of EI in accelerating recruitment}

In line with results of the study, the content analysis tied up to thematic analysis points to the following recommendations that would boost the UAE organization's hiring process, improve job performance and deplete employees' turnover, and enhance employees' retention through technology:

- UAE companies need to incorporate emotional intelligence online assessment in the hiring process across positions even during the pandemic.

- Trainings and development programs for EI enhancement should be implemented even online to keep employees motivated and armed with proper social knowledge.

- Emotional intelligence online assessment should be utilized as basis in employees' appraisal, employees' job performance evaluation, and employees' promotion.

\section{CONCLUSION}

The entirety of the research shows the implication of emotional intelligence in various aspects of human life, in personal and professional; and its effectiveness was validated through the data contributed by survey participants. The significance of emotional intelligence in work settings is to be contemplated as highly emotionally intelligent employee is a good performer and can be a great leader compared to an employee with high intelligence quotient (Sergio et al., 2013; Sergio et al., 2015). Moreover, it is concurred that an individual with superior EI stays longer in the company which can be a great remedy for rapid employee turnover which is a great challenge most of the companies are facing, hence, the findings conformed with the research done by Atak, et al., 2015. This research concludes that this is the best time for HR people and hiring managers to be their company's greatest contributor of success by hiring the right people through integration of emotional intelligence in the hiring process with the guidance of this research study, especially at the time of the pandemic. HR practitioners and mangers are in favor of EI implementation in the recruitment process and as proven in the research, it can foretell job performance. This research further concludes that hiring an emotionally intelligent employee is an asset to the company which can be a great support to business sustainability and can augment productivity.

\section{REFERENCES}

[1] Atak, M. \& Ceylan, I. (2015). Use of emotional intelligence on the selection of human resources. The Journal of Industrial Relations \& Human Resources, 17(4), pp. 239-258.

[2] Aydin, M. A. et al. (2005). The impact of IQ and EQ on pre-eminent achievement in 
organizations: implications for the hiring decision of HRM specialists. The International Journal of Human Resource Management, 16(5), pp. 701-719.

[3] Bar-On, R., (1997). The Bar-On Emotional Quotient Inventory (EQ-i): A test of emotional intelligence.. s.l.:s.n. Bill, T. (2011). Harvard Busines Review. Available at: $\quad$ https://hbr.org/2011/02/hire-forattitude-train-for-sk [Accessed 2 February 2020].

[4] Cherniss, C. (2000). Emotional Intelligence: What it is and why it matters. Consortium for research on emotional intelligence in the organizations.

[5] Cherry, K. (2020). 5 Components of Emotional Intelligence. Available at: https://www.verywellmind.com/componen ts-of-emotional-intelligence-2795438

[Accessed 23 February 2020].

[6] Cottrell, R. R. \& McKenzie, J. F. (2011). Health Promotion and Education Research Methods.

[7] Craig, H., n.d. The Theories of Emotional Intelligence Explained. Available at: https://www.searchnewworld.com/search/s earch2.html?partid=rolbng \&p=emotional+ intelligence + theory\&subid $=004$ [Accessed 18 February 2020].

[8] Elfenbein, H. A., Eisenkraft, N. \& Barsade, S. G. (2015). The Social Perception of Emotional Abilities: Expanding what we know about observer ratings of emotional intelligence. American Psychological Association, 15(1), pp. 17-34.

[9] Enotes, n.d. Why is business so important to a country's economy?. [Online] Available at: https://www.enotes.com/homeworkhelp/why-buisness-important-countryeconomy-474583 [Accessed 21 January 2020].

[10] Fox, S. \& Spector, P. (2002). Emotions in the workplace the neglected side of organizational life introduction, human resource. Management Review, Volume 12, pp. 167-171.

[11] Gayathri, N. \& Meenakshi, D. K. (2013). A literature review of emotional intelligence. Research Gate, 2(3), pp. 42-51.

[12] Ghose, T. (2013). Emotional Smarts Tied to General IQ. [Online] Available at: intelligence does depend on basic cognitive abilities, like attention and perception and memory and language. But it also depends on interacting with other people. We're fundamentally social beings and our understanding not only involves basic cognitive a [Accessed 16 February 2020].

[13] Goleman, D. (2004). What Makes a Leader?. Harvard Business Review, pp. 413.

[14] Hoffman, P. E. \& Sergio, R.P. (2020) Understanding the Effects of Toxic Leadership on Expatriates' Readiness for Innovation: An Uzbekistan Case. Journal of Eastern European and Central Asian Research, 7(1), 26-38.

[15] Hppy, n.d. When Numbers Fall: 4 Negative Effects of Employee Turnover. [Online] Available at: https://gethppy.com/employeeturnover/numbers-fall-4-negative-effectsemployee-turnover [Accessed 22 January 2020].

[16] Jacka, M. J. (2018). Emotional Intelligence can help auditors build and maintain positive, productive relationships throughout the organization. Internal Auditor, pp. 36-42.

[17] Joseph, D. L., Newman, D. A., Newman, J. J. \& O'Boyle, E. (2015). Why Does SelfReported Emotional Intelligence Predict Job Performance? A Meta-Analytic Investigation of Mixed EI. Journal of Applied Psychology, 100(2), pp. 298-342.

[18] Library, U., n.d. Theoretical \& Conceptual Frameworks: Introduction to Frameworks. [Online] Available at: https://www.searchnewworld.com/search/s earch2.html?partid=rolbng\&p=what + is + th 
e+purpose+of+theoretical+and+conceptual +framework\&subid=004 [Accessed 18 February 2020].

[19] Marcano, E.R. and Sergio, R.P. (2011). Psychological Capital: Implications for Business Schools, The International Journal of Business and Management Research, 4(1), 19-42.

[20] Mayer, J. D., Caruso, D. R. \& Salovey, P. (1999). Emotional intelligence meets traditional standards for an intelligence. Intelligence, Issue 27, pp. 267-298.

[21] Mayer, J. D., Roberts, R. D. \& Barsades, S. G. (2008). Human abilities: emotional intelligence. Annual Review of Psychology, Issue 59, pp. 507-536.

[22] Need, S. y., n.d. Interpersonal Skills. [Online] Available at: https://www.skillsyouneed.com/interperso nal-skills.html [Accessed 5 February 2020].

[23] Nicholls, S., Wegener, M., Bay, D. \& Cook, G. L., (2012). Emotional Intelligence Test: Potential Impacts on Hiring Process for Accounting Students. Accounting Education: an international journal, 21(1), pp. 75-95.

[24] Reference, n.d. What Is the Importance of Research?. [Online] Available at: https://www.reference.com/worldview/importance-researche040f288244d860f [Accessed 24 January 2020].

[25] Reference, n.d. Why Are Employees Important to a Business?. [Online] Available at: https://www.reference.com/businessfinance/employees-important-businessf0f1cd6a82d4e05a [Accessed 6 January 2020].

[26] Rouse, M. \& Cole, B., n.d. Emotional intelligence. [Online] Available at: https://searchcio.techtarget.com/definition/ emotional-intelligence

[27] Salovey, P. \& Mayer, J. (1990). Emotional intelligence. Imagination, cognition and personality, 9(3), pp. 185-211.
[28] Search, I. (2018). Emotional Intelligence: What Makes Business Leaders Stand Out From the Crowd?. [Online] Available at: https://www.imsa-

search.com/articles/emotional-intelligencemakes-business-leaders-stand-crowd/ [Accessed 07 February 2020].

[29] Sergio, R.P. (2011). The Software Component of the Mind Vis-à-vis Job Performance: Perspectives and Implications, International Review of Social Sciences and Humanities, 1(1), 7583.

[30] Sergio, R. P. \& Marcano, E. R. (2013). Emotional Intelligence and Demographic Profile Variables As Predictors Of Job Performance Among Bank Managers In The Middle East. International Journal of Arts \& Sciences, 6(2), 377-388.

[31] Sergio, R. P., Marcano, E. R., Ocampo, J. G. \& Oribiana, M. Z. (2016). Developing Compassion: Constructs, Perspectives, and Implications for Business Schools. IAMURE International Journal of Business and Management, 13(1), 38-54.

[32] Sergio, R. P., Ormita, L. G.-L., Dungca, A. L. \& Gonzales, O. J. (2015). Emtional intelligence, work/family conflict and work values among customer service representatives: Basis for organizational support. Journal of Eastern European and Central Asian Research, 2(1), pp. 1-9.

[33] University, S. C. S. (2017). limitations and delimitations in research. [Online] Available at: https://blog.stcloudstate.edu/ims/2017/03/2 8/limitations-and-delimitations-inresearch/ [Accessed 13 March 2020].

[34] Viskupicova, H. (2016). Emotionally intelligent leadership as a key determinat of strategic and effective management of human capital. Journal of Human Resource Management, XIX(1), pp. 68-78. 